\title{
Gene expression related to molybdenum enzyme biosynthesis in response to molybdenum deficiency in winter wheat
}

\author{
Zhaojun $\mathrm{Nie}^{1,2}$, Chengxiao Hu${ }^{1}$, Qiling Tan ${ }^{1}$, Xuecheng Sun ${ }^{1 *}$ \\ ${ }^{1}$ Research Center of Trace Elements, Huazhong Agricultural University, Wuhan 430070, China \\ "Corresponding author: sxccn@mail.hzau.edu.cn \\ ${ }^{2}$ Resources and Environment College, Henan Agricultural University, Zhengzhou 450002, China
}

\begin{abstract}
Molybdenum (Mo) is an essential trace element for higher plants. Mo enzyme biosynthesis is regulated by several plant genes. A hydroponic trial was conducted to investigate the effect of Mo deficiency on the expression of genes that are related to Mo enzyme biosynthesis in winter wheat. The results showed that Mo deficiency decreased the activities of nitrate reductase (NR), sulphite oxidase (SO), aldehyde oxidase (AO) and xanthine dehydrogenase $(\mathrm{XDH})$ in the leaves or roots of winter wheat by regulating the expression of $N R, S O, A O$ and $X D H$ genes. Mo deficiency induced the expression of TaCnx2 and TaCnx5, which might result in the accumulation of cyclic pyranopterin monophosphate (cPMP) and molybdopterin (MPT) in wheat. Mo deficiency significantly decreased TaCnxl expression, which is expected to reduce molybdenum cofactor (Moco) formation. Moco shortage induced the expression of TaAba3 in winter wheat. The blockade of Moco biosynthesis under conditions of Mo deficiency might decrease the activities of Mo enzymes.
\end{abstract}

Keywords: Molybdenum deficiency, molybdenum enzyme biosynthesis, gene expression, winter wheat

Abbreviations: Mo, molybdenum; NR, nitrate reductase; SO, sulphite oxidase; AO, aldehyde oxidase; XDH, xanthine dehydrogenase; Moco, molybdenum cofactor; GTP, guanosine 5'-triphosphate; cPMP, cyclic pyranopterin monophosphate; MPT, molybdopterin; MPT-AMP, adenylated molybdopterin; ABA, abscisic acid.

\section{Introduction}

The trace element Molybdenum (Mo) is essential for plant growth. More than 50 Mo enzymes have been found in all organisms and catalyse a variety of redox reactions, but only four (nitrate reductase (NR), sulphite oxidase (SO), xanthine dehydroge- nase (XDH), and aldehyde oxidase (AO)) have been found in plants thus far (Mendel and Leimkühler, 2015). Mo enzymes participate in various metabolic processes, such as nitrate assimilation, sulphite detoxification, phytohormone synthesis and purine catabolism, in plants (Mendel and Leimkühler, 2015). 
Mo deficiency induces the yellowing and whiptail of leaves, as well as depressed photosynthesis, cold resistance, and drought resistance, characteristics that are thought to be related to the inactivation of Mo enzymes under Mo deficiency (Kaiser et al., 2005).

Mo uptake and transport in plants require the involvement of some proteins, such as MOT1 and MOT2. The specific transporter MOT1 and MOT2 are required for efficient uptake, translocation and storage of molybdate. Mo deficiency reduced MOT1 expression and induced MOT2 gene in plant shoot, and then decreased Mo uptake and transfer from root to shoot (Baxter et al., 2008; Gasber et al., 2011). After being taken up by plants, Mo exhibits no bioactivity unless it is combined with a ubiquitous pterin-based $\mathrm{Mo}$ cofactor (Moco) (Zaman et al., 2014), which forms part of the active centre of all Mo enzymes in plants (Mendel and Leimkühler, 2015). Moco biosynthesis includes three steps (Mendel and Leimkühler, 2015). In the first step, guanosine 5'-triphosphate (GTP) is transformed into the sulphur-free pterin compound, cyclic pyranopterin monophosphate (cPMP, also known as precursor $\mathrm{Z}$ ), a reaction that is catalysed by two proteins, $\mathrm{CNX} 2$ and $\mathrm{CNX} 3$, which are located in the mitochondria (Teschner et al., 2010). The second step is the synthesis of molybdopterin (MPT), which is catalysed by MPT synthase, comprising CNX6 and CNX7. The formation of MPT is not a catalytic reaction; therefore, MPT synthase needs to be reactivated for the following cPMP conversion cycle after each reaction step. MPT-synthase sulphurase, $\mathrm{CNX}$, catalyses this separate resulphuration via sulphur transfer. Finally, Mo is transferred into the MPT and forms Moco. CNX1 adenylates the Moco precursor MPT to MPT-AMP and subsequently catalyses the insertion of molybdate into MPT, generating Moco (Llamas et al., 2006). ABA3 is a Moco sulphurase that is required for the activation of $\mathrm{AO}$ and $\mathrm{XDH}$; thus, it plays an important role in the biosynthesis of $\mathrm{AO}$ and $\mathrm{XDH}$
(Bittner, Oreb, and Mendel, 2001). Mo enzymes are activated after insertion of Moco. The activity or protein synthesis of these enzymes are regulated by their genes. For example, the transcript of $N R$ regulates its activity and synthesis (Miller and Cramer, 2005). The functions of $S O$ and $A O$ gene are to encode the $\mathrm{SO}$ and $\mathrm{AO}$ involving in sulfur metabolism and hormone biosynthsis, respectivelly (Eilers et al., 2001; Yesbergenova et al., 2005). Like AO, XDH activity requires a post-translational of the holoenzyme, but it is also regulated by transcript of $\mathrm{XDH}$ gene especially in environment-stressed plants (Hesberg et al., 2004). In principle, the transcript level of Mo enzyme gene affects biosynthesis amounts of the proteins directly. The gene expression of the four Mo enzymes could be regulated by environmental factor, such as light, low temperature, drought and so on.

Previous studies have found that Mo deficiency slightly induced the expression of $C N X 2, C N X 5$, $C N X 6, A B A 3$, and MOT2 in a Arabidopsis thaliana T-DNA inserted mutant, mot1-1 (Ide et al., 2011). In addition, several reports also show Mo deficiency can decrease the activities of Mo enzyme such as NR, AO and XDH in plant (Sun et al., 2009; Yesbergenova et al., 2005). We speculated Mo deficiency might affect the biosynthesis of Moco and Mo enzymes through regulating the expression of above genes in winter wheat. To get a better understanding of the reason for the decrease in Mo enzyme activities, we investigated the expression of genes related to the biosynthesis of Mo enzymes in winter wheat.

\section{Materials and Methods}

\subsection{Plant material}

Winter wheat (Triticum aestivum) 'Jing852' seeds were disinfected in a solution of $0.5 \% \mathrm{NaClO}$ before being germinated in deionized water (resistivity $>18.25$ 
$\mathrm{M} \Omega . \mathrm{cm}$ at $25^{\circ} \mathrm{C}$ ) at $25^{\circ} \mathrm{C}$ for $5 \mathrm{~d}$. After germination, the seedlings were transferred to $10-\mathrm{L}$ plastic boxes containing nutrient solutions including $4 \mathrm{mmol} \mathrm{L}^{-1}$ $\mathrm{Ca}\left(\mathrm{NO}_{3}\right)_{2} \cdot 4 \mathrm{H}_{2} \mathrm{O}, 6 \mathrm{mmol} \mathrm{L}^{-1} \mathrm{KNO}_{3}, 1 \mathrm{mmol} \mathrm{L}^{-1} \mathrm{NH}_{4} \mathrm{H}-$ ${ }_{2} \mathrm{PO}_{4}, 2 \mathrm{mmol} \mathrm{L}^{-1} \mathrm{MgSO}_{4} \cdot 7 \mathrm{H}_{2} \mathrm{O}, 100 \mu \mathrm{mol} \mathrm{L}^{-1}$ EDTAFe, $46 \mu \mathrm{mol} \mathrm{L}^{-1} \mathrm{H}_{3} \mathrm{BO}_{3}, 9 \mu \mathrm{mol} \mathrm{L}-1 \mathrm{MnCl}_{2} \cdot 4 \mathrm{H}_{2} \mathrm{O}, 0.8$ $\mu \mathrm{mol} \mathrm{L}^{-1} \mathrm{ZnSO}_{4} \cdot 7 \mathrm{H}_{2} \mathrm{O}$, and $0.3 \mu \mathrm{mol} \mathrm{L}^{-1} \mathrm{CuSO}_{4} \cdot 5 \mathrm{H}_{2} \mathrm{O}$, adjusted to a $\mathrm{pH}$ of 6.0. Mo was added to the nutrient solutions as $\mathrm{Na}_{2} \mathrm{MoO}_{4} \cdot 2 \mathrm{H}_{2} \mathrm{O}$ at two rates: 0 (-Mo) and $1 \mu \mathrm{mol} \mathrm{L}{ }^{-1}(+\mathrm{Mo})$. Each treatment was replicated three times. Quarter- and half-strength nutrient solutions were used in the first and second weeks, respectively, and full-strength solutions were then used until the seedlings were sampled. The solutions were refreshed every three days. All vessels that were used in the experiment were dipped in $5 \% \mathrm{HCl}$ for one week and then washed with deionized water a minimum of 3 times. To minimize possible Mo contamination, the water used to prepare the nutrient solutions was deionized, and pure reagents were used. The plants were grown for 30 days in a glasshouse under controlled environmental conditions using a light/dark regime of $12 / 12 \mathrm{~h}$, corresponding air temperatures of $22 / 18^{\circ} \mathrm{C}$, a photon flux density of approximately $500 \mu \mathrm{mol} \mathrm{m} \mathrm{m}^{-2} \mathrm{~s}^{-1}$ and a relative humidity of approximately $65 \%$.

\subsection{Assay of Mo-enzyme activities}

NR activity was assayed according to the method described by Evans and Nason (1953). The leaves or roots $(0.5 \mathrm{~g})$ were homogenized in $4 \mathrm{~mL}$ icecold extraction medium $\left(\mathrm{pH} 8.7,0.025 \mathrm{~mol} \mathrm{~L}^{-1}\right.$ potassium phosphate, $1 \mathrm{mmol} \mathrm{L}^{-1}$ EDTA, $10 \mathrm{mmol} \mathrm{L}^{-1}$ L-cysteine), and the homogenate was then centrifuged at $4,000 \times g$ for $15 \mathrm{~min}$ at $4{ }^{\circ} \mathrm{C}$. The assay mixture contained $1.2 \mathrm{~mL}$ of $0.1 \mathrm{~mol} \mathrm{~L}^{-1}$ potassium phosphate buffer ( $\mathrm{pH} 7.5$ ) containing $0.1 \mathrm{~mol} \mathrm{~L}^{-1} \mathrm{KNO}_{3}, 0.4 \mathrm{~mL}$ of $2.62 \mathrm{mmol} \mathrm{L}^{-1} \mathrm{NADH}$, and $0.4 \mathrm{~mL}$ of enzyme extract. The mixture was incubated at $25^{\circ} \mathrm{C}$ for $15 \mathrm{~min}$, after which the reaction was stopped by adding $1 \mathrm{~mL}$ of $1 \% \mathrm{w} / \mathrm{v}$ sulphanilamide in $3.0 \mathrm{~mol} \mathrm{~L}^{-1} \mathrm{HCl}$. N-(1napthyl) ethylene diamine hydrochloride reagent was then added $(1 \mathrm{~mL}, 0.02 \% \mathrm{w} / \mathrm{v})$, and the contents were mixed by inverting the tubes. The colour was allowed to develop for $15 \mathrm{~min}$ before the mixture was centrifuged at $4,000 \times g$ for $5 \mathrm{~min}$ to remove turbidity. The absorbance was determined by reading each sample against its own blank (a complete reaction except that NADH was absent) in a spectrophotometer at $540 \mathrm{~nm}$. $\mathrm{AO}$ and $\mathrm{XDH}$ activities were assayed according to the methods described by Yesbergenova et al. (2005). Tissues were homogenized in ice-cold extraction medium containing $250 \mathrm{mmol} \mathrm{L}^{-1}$ Tris- $\mathrm{HCl}(\mathrm{pH} 8.5), 1$ mmol L-1 EDTA, $1 \mathrm{mmol} \mathrm{L}^{-1}$ DTT, 3 mmol L-1 GSH, and 3\% (w/v) PVPP. Samples comprising $1 \mathrm{~g}$ of leaves or roots were extracted in 3 or $2 \mathrm{~mL}$ of buffer $(1: 3$ and $1: 2, w / v)$, respectively. The homogenates were then centrifuged at $12,000 \times g$ for 20 min at 4 ${ }^{\circ} \mathrm{C}$. AO activity was assay by monitoring the decrease of absorbance at $600 \mathrm{~nm}$ using a UV 2100 spectrophotometer (Shimadzu, Kyoto, Japan); DCIP was used as an electron donor. The AO reaction mixture $(1 \mathrm{~mL})$ contained $100 \mathrm{~mL}$ of enzyme extract, $50 \mathrm{mmol} \mathrm{L}^{-1}$ potassium phosphate (pH 7.4), 0.002\% (w/v) DCIP, 0.1 mmol L-1 PMS, and $2 \mathrm{mmol} \mathrm{L}^{-1}$ indole-3-aldehyde. The XDH reaction mixture $(1 \mathrm{~mL})$ contained $100 \mathrm{~mL}$


$0.002 \%(\mathrm{w} / \mathrm{v})$ DCIP, $0.1 \mathrm{mmol} \mathrm{L}^{-1}$ PMS, and 0.6 mmol L ${ }^{-1}$ hypoxanthine. $\mathrm{AO}$ and $\mathrm{XDH}$ activities were expressed as nanomoles DCIP reduced per milligram of protein per minute.

SO activity was assayed according to the method described by Eilers et al. (2001). The leaves or roots $(1 \mathrm{~g})$ were homogenized in $3 \mathrm{~mL}$ ice-cold extraction medium containing $100 \mathrm{mmol} \mathrm{L}^{-1}$ HEPES ( $\mathrm{pH}$ 7.3), $1 \mathrm{mmol} \mathrm{L}^{-1}$ EDTA, 5\% (v/v) glycerol, $1 \mathrm{mmol} \mathrm{L}^{-1}$ $\mathrm{Na}_{2} \mathrm{MoO}_{4}$, and $1 \mathrm{mmol} \mathrm{L}^{-1} \mathrm{PMSF}$. The homogenate was centrifuged at $21,000 \times g$ for $20 \mathrm{~min}$ at $4{ }^{\circ} \mathrm{C}$. SO 
activity assay was monitored by following the reduction of ferricyanide at $420 \mathrm{~nm}$ using a UV $2100 \mathrm{spec}-$ trophotometer (Shimadzu, Kyoto, Japan). Sodium sulphite $\left(4 \mu \mathrm{L}, 0.1 \mathrm{~mol} \mathrm{~L}^{-1}\right)$ was added to a cuvette containing $20 \mu \mathrm{L}$ of the enzyme extract, $20 \mathrm{mmol} \mathrm{L}^{-1}$ Tris- $\mathrm{HCl}$ (pH 8.0), $0.1 \mathrm{mmol} \mathrm{L}^{-1}$ EDTA, and $0.4 \mathrm{mmol}$ $\mathrm{L}^{-1}$ ferricyanide. One unit of SO activity was defined as the conversion of $1 \mu \mathrm{mol}$ of sulphite per milligram of protein per minute.

Soluble protein concentrations in the assays were measured using crystalline BSA as a reference (Bradford, 1976).

\subsection{Determination of gene expression levels}

Total RNA was extracted from the roots using Trizol reagent (Invitrogen, USA). First-strand cDNA was synthesized from $1 \mu \mathrm{g}$ of total RNA using M-MLV
Reverse Transcriptase (Promega, USA) according to the manufacturer's instructions, and the product was diluted to $1000 \mathrm{ng} \mu \mathrm{L}^{-1}$. cDNA was used as the template in a real-time PCR reaction using a $\mathrm{CFX}^{96}$ Real-Time PCR Detection System (Bio-Red, USA) and SYBR green for product detection at the end of each amplification cycle (Karsai et al., 2002). Real-time PCR was carried out according to Van Riet et al. (2006). Primers for the genes of interest were designed by Primer Premier 5.0 based on wheat gene sequences derived from NCBI (http://www.ncbi.nlm. nih.gov/) or CBFGL (http://compbio.dfci.harvard. edu/tgi/) according to Quackenbush et al. (2001), as listed in Table 1. The wheat Actin gene was used as a reference for all genes of interest. The relative quantities of the transcripts were calculated according to the method of Pfaffl (2001).

Table 1. Primers used for real-time PCR amplification

\begin{tabular}{cccc}
\hline Gene & $\begin{array}{c}\text { Gene Index } \\
\text { No. }\end{array}$ & Strand & Primer sequence 5' to 3' \\
\hline TaCnx2 & TC381184 & Forward & GCCCCTCAGAGGTGAGCTTG \\
& & Reverse & TGTCACGCAGGGAAGAAGGA \\
TaCnx5 & TC419777 & Forward & TTGGATGTACGGCCTGCTCA \\
& & Reverse & GGACAGCGCTCTGTGAGTCG \\
TaCnx1 & TC385680 & Forward & AGGGAAGCCATTGACATTTG \\
& & Reverse & TCACTGCACGATGAAACTCC \\
TaAba3 & TC385542 & Forward & TTGGATGTACGGCCTGCTCA \\
& & Reverse & GGACAGCGCTCTGTGAGTCG \\
NR & TC457165 & Forward & TCAACGAGCTCAACACCAAC \\
& & Reverse & CAGAAGCACCAGCACCAGTA \\
SO & TC375951 & Forward & CCGTGTGGTCGTACCTGGTG \\
& & Reverse & CACATCTTCCAGGGGTGCAA \\
AO & TC454526 & Forward & TGAAGCAGATGACGGCGTTC \\
& & Reverse & AAGAGCACGGTGCACGACTG \\
XDH & TC409845 & Forward & CGCGGCATCTGTAGCTTCCT \\
& & Reverse & GCACGCTCCAAGACTGCAAG \\
TaActin & AB181991.1* & Forward & ACTGGGATGACATGGGGAA \\
& & Reverse & ACCGCTGGCATACAAGGAC \\
\hline
\end{tabular}

Note: *Sequences derived by cDNA/genomic DNA isolation and sequencing; TC gene index numbers were derived from TIGR gene indices (Quackenbush et al., 2000). 


\subsection{Analysis of Mo concentration}

Plant samples were ground, carbonized and ashed. Mo concentrations were determined using polarographic catalytic wave analysis using a JP-2 oscilloscope polarograph according to Wan et al. (1988).

\subsection{Statistical analysis}

Data are presented as the averages of three replicates. The results were statistically analysed using the Duncan multiple comparison as implemented in SPSS 18 software. All statistically significant differences were tested at $\mathrm{P}<0.05$.

\section{Results}

\subsection{Mo concentration}

Pronounced differences were observed for Mo concentrations in the tissues of winter wheat. Mo concentrations in the shoots and roots were significantly lower after -Mo treatment than after + Mo treatment (Table 2).

Table 2 Molybdenum concentrations in the shoots and roots of winter wheat. -Mo and + Mo treatments represent plants that were fertilized with 0 and $1 \mu \mathrm{mol} \mathrm{Mo} \mathrm{L}-1\left[\mathrm{Na}_{2} \mathrm{MoO}_{4} \cdot 2 \mathrm{H}_{2} \mathrm{O}\right]$, respectively. Data are the means of three replicates $( \pm \mathrm{se})$ with ten plants in each replicate per treatment. Different letters in a column indicate significant differences at P 0.05 as determined by ANOVA followed by Duncan's test.

\begin{tabular}{ccc}
\hline \multirow{2}{*}{$\begin{array}{c}\text { Treatme } \\
\text { nts }\end{array}$} & \multicolumn{2}{c}{ Mo concentration $\left(\mu \mathrm{g} \mathrm{g}^{-1}\right)$} \\
\cline { 2 - 3 } & Shoot & Root \\
\hline -Mo & $0.084 \pm 0.009^{\mathrm{b}}$ & $0.293 \pm 0.017^{\mathrm{b}}$ \\
+ Mo & $4.439 \pm 0.406^{\mathrm{a}}$ & $5.055 \pm 1.150^{\mathrm{a}}$ \\
\hline
\end{tabular}

\subsection{Mo enzyme activities and gene expression}

Mo deficiency decreased NR activity in the leaves and roots of winter wheat 2.5-fold and 2.6-fold, respectively (Figure 1A). There was no perceptible difference in the SO activity of leaves between treatments, but the activity in roots was approximately 1.7-fold lower under Mo deficiency (Figure
1B). Similarly, Mo deficiency had no significant influence on AO activity in leaves but significantly decreased AO activity in roots 3.3-fold (Figure 1C). XDH activity was significantly decreased (1.2-fold) in leaves of winter wheat in response to Mo deficiency, but no significant difference was observed in roots between the treatments (Figure 1D). 

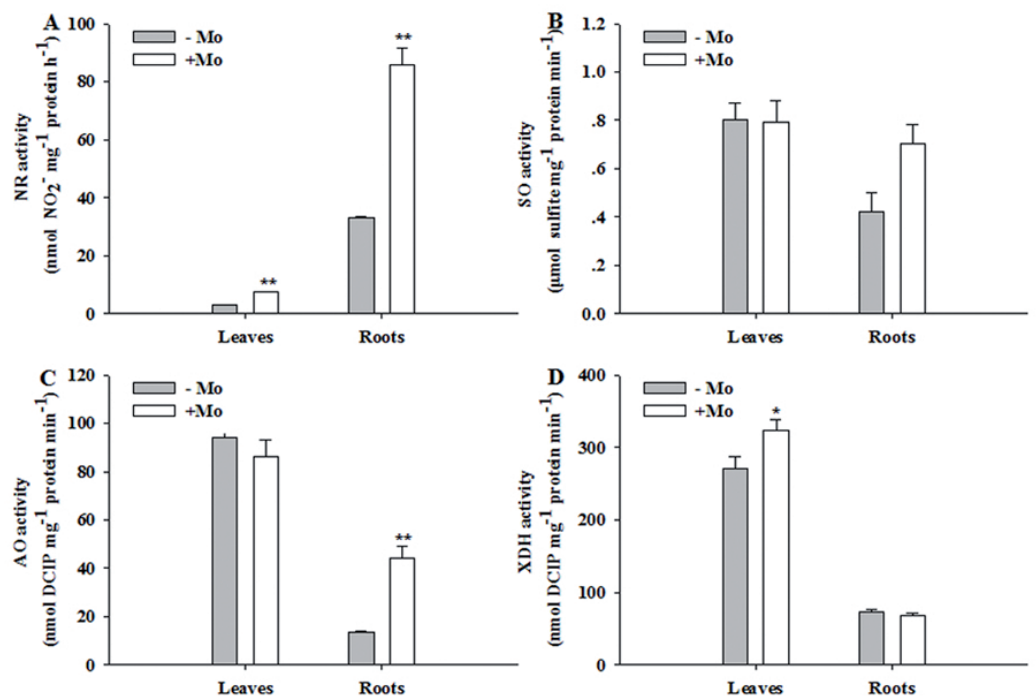

Figure 1 Activities of NR (A), SO (B), AO (C) and XDH (D) in the leaves and roots of winter wheat. -Mo and + Mo treatments represent plants that were fertilized with 0 and $\left.1 \mu \mathrm{mol} \mathrm{Mo} \mathrm{L}-1 \mathrm{Na}_{2} \mathrm{MoO}_{4} \cdot 2 \mathrm{H}_{2} \mathrm{O}\right]$, respectively. Data are the means of three replicates $( \pm$ se) with four plants in each replicate per treatment. $*$ and ** indicate differences between treatments as determined by ANOVA followed by Duncan's test $(*: \mathrm{P}<0.05, * *: \mathrm{P}<0.01)$.

Mo deficiency significantly induced the expression of $N R$ in leaves of winter wheat (12-fold), but no significant difference was found in roots (Figure 2A). The expression of genes encoding other Mo enzymes were also tested; $S O$ in leaves, $A O$ in leaves and roots and $X D H$ in roots were all significantly decreased (approximately 3.0-fold, 3.8-fold, 5.5-fold and 15-fold, respectively) under Mo deficiency (Figure 2B, C and D). However, no significant difference was found between - Mo and + Mo treatments regarding $S O$ expression in the roots and $X D H$ expression in the leaves of winter wheat (Figure 2B and D). 

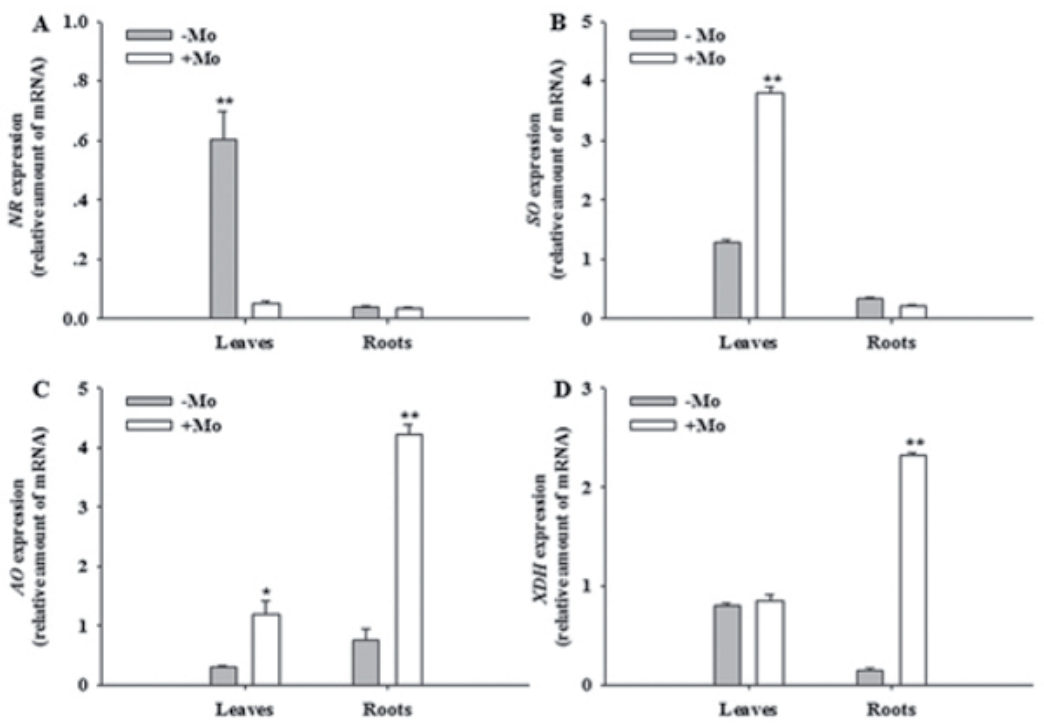

Figure 2 Expression of $N R(\mathrm{~A}), S O(\mathrm{~B}), A O(\mathrm{C})$ and $X D H(\mathrm{D})$ in the leaves and roots of winter wheat. -Mo and +Mo treatments represent plants that were fertilized with 0 and $1 \mu \mathrm{mol} \mathrm{Mo} \mathrm{L}{ }^{-1}\left[\mathrm{Na}_{2} \mathrm{MoO}_{4} \cdot 2 \mathrm{H}_{2} \mathrm{O}\right]$, respectively. Data are the means of three replicates $( \pm \mathrm{se})$ with four plants in each replicate per treatment. * and ** indicate differences between treatments as determined by ANOVA followed by Duncan's test (*: $\mathrm{P}<0.05, * *: \mathrm{P}<0.01)$.

\subsection{Expression of genes involved in the biosynthesis and sulphonation of Moco}

Compared with the +Mo treatment, TaCnx 2 mRNA levels in leaves and roots were increased 2.6-fold and 3.1-fold, respectively, under -Mo treatment (Figure 3A). Mo deficiency similarly induced in- creased TaCnx5 mRNA levels in leaves and roots, as shown in Figure 3B. TaCnxl expression in leaves and roots was decreased by Mo deficiency (approximately 1.3-fold and 1.8-fold, respectively; Figure 3C). TaAba 3 expression in leaves and roots was induced by Mo deficiency (approximately 1.2fold and 2.0-fold, respectively; Figure 3D). 

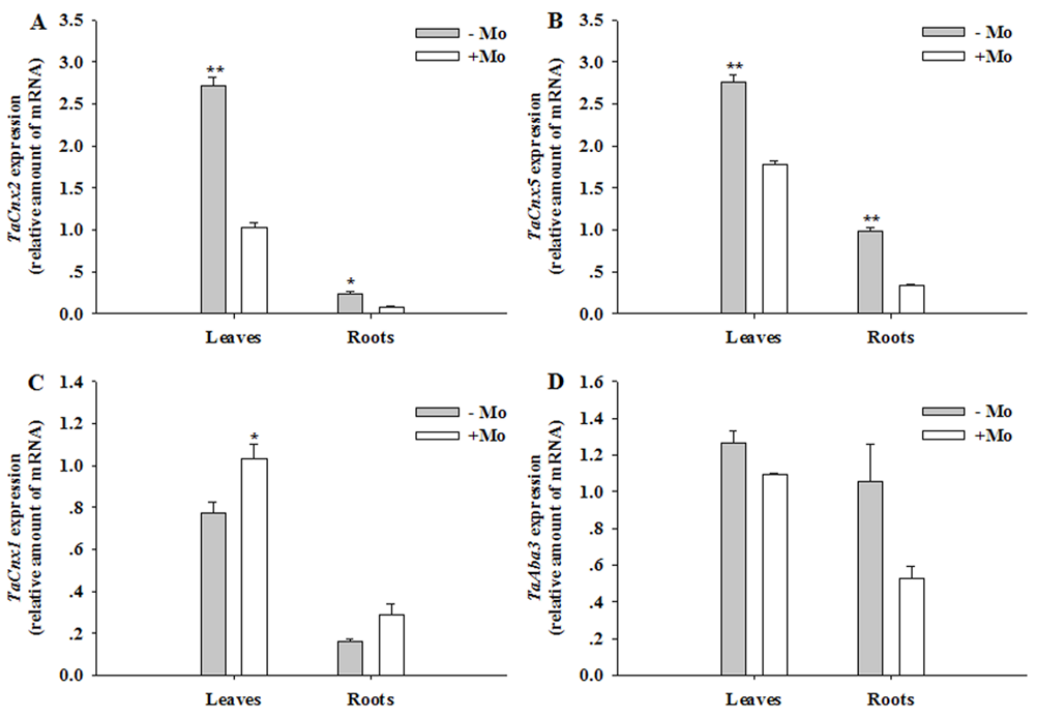

Figure 3. Expression of TaCnx2 (A), TaCnx5 (B), TaCnx1 (C) and TaAba3 (D) in the leaves and roots of winter wheat. -Mo and +Mo treatments represent plants that were fertilized with 0 and $1 \mu$ mol Mo $\mathrm{L}^{-1}\left[\mathrm{Na}_{2} \mathrm{MoO}_{4} \cdot 2 \mathrm{H}_{2} \mathrm{O}\right]$, respectively. Data are the means of three replicates $( \pm \mathrm{se})$ with four plants in each replicate per treatment. * and $* *$ indicate differences between treatments as determined by ANOVA followed by Duncan's test $(*: \mathrm{P}<0.05, * *: \mathrm{P}<0.01)$.

\section{Discussion}

A reasonably proportional relationship exists between enzyme activity and Mo concentration in plants (Hew and Chai, 1984). In our experiment, Mo deficiency significantly decreased the activities of $\mathrm{NR}, \mathrm{SO}, \mathrm{AO}$ and $\mathrm{XDH}$ in the tissues of winter wheat (Figure 1); this was due to decreased Mo concentrations in the tissues (Table 2). These results are highly consistent with our earlier results (Sun et al., 2009).

As previously mentioned, Mo enzymes have been identified in plants, including NR, SO, AO and $\mathrm{XDH}$ (Mendel and Leimkühler, 2015). NR is involved in primary nitrogen assimilation (MárquezQuiroz et al., 2014). The activity of NR can be regulated by mRNA (transcription) and protein (translation) synthesis level, as well as post-translation modifications (Miller and Cramer, 2005). $N R$ mRNA is induced by nitrate, light, and downstream $\mathrm{N}$ assimilation products such as amino acids or C products. NR protein synthesis and posttranslation modifications are controlled by the reversible phosphorylation of the protein, and other environmental conditions such as light/dark transitions and $\mathrm{CO}_{2}$ removal. It revealed that there was an complicated process in regulating the activity of NR (Miller and Cramer, 2005). In our experiments, Mo deficiency induced $N R$ gene expression but decreased NR activity in the leaves of winter wheat (Figure 1A and 2A). The observed increase in $N R$ gene expression might be a compensatory response to the decrease in nitrate assimilation that occurs under Mo deficiency, and the observed decrease in 
NR activities might be related to lack of Moco or post-translation modifications under Mo deficiency (Ide et al., 2011). Mo deficiency decreases NR activity, thereby depressing nitrogen metabolism (Hu, Wang, and Wei, 2002). SO oxidizes sulphite to sulphate and protects plant cells from the toxic effects of endogenously arising sulphite (Lang et al., 2007). Mo deficiency decreased SO activity and its expression (Figure $1 \mathrm{~B}$ and $2 \mathrm{~B}$ ), indicating that sulphite detoxification was inhibited. $\mathrm{AO}$ has been shown to catalyse the synthesis of abscisic acid (ABA) (Kaiser et al., 2005). The observed decrease in $A O$ mRNA levels in the roots was consistent with the significant decrease in AO activity in the roots under Mo deficiency (Figure 1C and 2C) and with the results of Tiedge et al. (1997) and Hesberg et al. (2004), who reported that enzyme activities are determined by mRNA levels. Mo deficiency decreases AO activity and endogenous ABA levels in winter wheat (Sun et al., 2009), thereby affecting cold resistance in winter wheat (Li et al., 2001). XDH is involved in purine catabolism and activated oxygen metabolism during senescence (Zimmer and Mendel, 1999). Mo deficiency resulted in a decline in XDH activity and $X D H$ gene expression (Figure 1D and 2D), suggesting that Mo deficiency inhibits purine catabolism and accelerates senescence. In short, Mo deficiency might depress nitrate assimilation, sulphite detoxification, ABA biosynthesis and purine catabolism by regulating Mo enzyme activities and their gene expression.

Moco is the active compound at the catalytic site of all Mo enzymes in nature except nitrogenase (Mendel and Leimkühler, 2015). CNX2, CNX5 and CNX1 are involved in Moco biosynthesis. CNX2 induces the transformation from GTP to cPMP (Balk and Lobréaux, 2005). Mo deficiency increased TaCnx2 mRNA levels in leaves and roots, which is expected to enhance the transformation from GTP to cPMP. CNX5 catalyses the resulphuration of MPT synthase to continuously generate MPT (Mendel and Leimkühler, 2015). Mo deficiency induced the expression of TaCnx5 (Figure 3B), indicating that Mo deficiency increases the regeneration of MPT synthase and the formation of MPT. Therefore, it was speculated that Mo deficiency induced the accumulation of cPMP and MPT by regulating the expression of TaCnx2 and TaCnx5. Ide et al. (2011) also reported that Mo deficiency slightly induced the expression of CNX2 and CNX5 in Arabidopsis thaliana mot1-1 shoots. CNX1 catalyses the insertion of molybdate into MPT, which is the last step in Moco biosynthesis (Kaufholdt et al., 2016). Mo deficiency significantly decreased the expression of TaCnxl in winter wheat leaves (Figure 3C), which might inhibit the production of Moco and result in the accumulation of cPMP and MPT in wheat (Figure $3 \mathrm{C}$ and Table 2). ABA3 catalyses the sulphonation of Mo-cofactor, which is essential for the biosynthesis of members of the XDH/AO family (Bittner, Oreb, and Mendel, 2001). Mo deficiency induced the expression of TaAba3 in the leaves and roots of winter wheat (Figure 3D), indicating that higher transcript levels of $A B A 3$ are needed under Moco deficiency.

\section{Conclusions}

The present study provides evidence that Mo deficiency affects the expression of genes that are related to Mo enzyme biosynthesis in winter wheat. Compared with Mo application treatment, Mo deficiency decreases Mo concentrations by 52.8-fold and 17.3fold in leaves and roots, respectively. Mo deficiency accordingly decreased NR activities by 2.5 -fold and 2.6-fold in leaves and roots, and decreased SO 
activity by 1.7-fold in leaves, AO activity by 3.3fold in roots, XDH activity by 1.2 -fold in leaves, respectively. Similarly, the expression of $S O, A O$, $X D H$ and TaCnxl were decreased from 1.3-fold to 15.0 -fold in leaves or roots. But NR, TaCnx2, TaCnx 5 and TaAba 3 were induced from 1.2-fold to 3.0-fold in leaves or roots in response to Mo deficiency. These results indicated Mo can regulated the mo-cofactor biosynthesis, and then affected the Mo-enzymes activities under a certain degree.

\section{Acknowledgements}

This work was supported by the National Natural Science Foundation of China (Program Nos. 41171240, 41201286 and 41501311) and the Fundamental Research Funds for the Central Universities (Program No. 2013PY135), and the 948 Project from the Ministry of Agriculture of China (2015-Z34 and 2016-X41).

\section{References}

Balk, J., Lobréaux, S. 2005. Biogenesis of ironsulfur proteins in plants. Trends Plant Sci. 10 (7):324-331.

Baxter, I., Muthukumar, B., Park, H. C., Buchner, P., Lahner, B., Danku, J., Zhao, K., Lee, J., Hawkesford, M. J., Guerinot, M. L. 2008. Variation in molybdenum content across broadly distributed populations of Arabidopsis thaliana is controlled by a mitochondrial molybdenum transporter (MOT1). Plos Genet. 4 (2):e1000004.

Bittner, F., Oreb, M., Mendel, R. R. 2001. ABA3 is a molybdenum cofactor sulfurase required for activation of aldehyde oxidase and xanthine dehydrogenase in Arabidopsis thaliana. J. Biol. Chem. 276 (44):40381-40384.
Bradford, M. M. 1976. Rapid and sensitive method for the quantitation of microgram quantities of protein utilizing the principle of protein-dye binding. Anal. Biochem. 72 (7):248-254.

Eilers, T., Schwarz, G., Brinkmann, H., Witt, C., Richter, T., Nieder, J., Koch, B., Hille, R., Hänsch, R., Mendel, R. R. 2001. Identification and biochemical characterization of Arabidopsis thaliana sulfite oxidase: a new player plant sulfur metabolism. J. Biol. Chem. 276 (50):46989-46994.

Evans, H. J., Nason, A. 1953. Pyridine nucleotidenitrate reductase from extracts of higher plants. Plant Physiol. 28 (2):233-254.

Gasber, A., Klaumann, S., Trentmann, O., Trampczynska, A., Clemens, S., Schneider, S., Sauer, N., Feifer, I., Bittner, F., Mendel, R. R. 2011. Identification of an Arabidopsis solute carrier critical for intracellular transport and interorgan allocation of molybdate. Plant Biol. 13 (5):710-718.

Hesberg, C., Hänsch, R., Mendel, R. R., Bittner, F. 2004. Tandem orientation of duplicated xanthine dehydrogenase genes from Arabidopsis thaliana differential gene expression and enzyme activities. J. Biol. Chem. 279 (14):1354713554.

Hew, C. S., Chai, B. W. 1984. Effect of light intensity, nitrate and molybdenum levels on nitrate assimilation in Choy Sam (Brassica chinensis). Paper read at International Congress on Soilless Culture.

Hu, C. X., Wang, Y. H., Wei, W. X. 2002. Effect of molybdenum applications on concentrations of free amino acids in winter wheat at different growth stages. J. Plant. Nutr. 25 (7):1487-1499. 
Ide, Y., Kusano, M., Oikawa, A., Fukushima, A., Tomatsu, H., Saito, K., Hirai, M. Y., Fujiwara, T. 2011. Effects of molybdenum deficiency and defects in molybdate transporter MOT1 on transcript accumulation and nitrogen/sulphur metabolism in Arabidopsis thaliana. J. Exp. Bot. 62 (4):1483-1497.

Kaiser, B. N., Gridley, K. L., BRADY, J. N., Phillips, T., Tyerman, S. D. 2005. The role of molybdenum in agricultural plant production. Ann. Bot. 96 (5):745-754.

Karsai, A., Müller, S., Platz, S., Hauser, M. T. 2002. Evaluation of a homemade SYBR green I reaction mixture for real-time PCR quantification of gene expression. Biotechniques. 32 (4):790-792, 794-796.

Kaufholdt, D., Baillie, C. K., Bikker, R., Burkart, V., Dudek, C. A., Pein, L. V., Rothkegel, M., Mendel, R. R., Hänsch, R. 2016. The molybdenum cofactor biosynthesis complex interacts with actin filaments via molybdenum insertase Cnx1 as anchor protein in Arabidopsis thaliana. Plant Sci. 244:8-18.

Lang, C., Popko, J., Wirtz, M., Hell, R., Herschbach, C., Kreuzwieser, J., Rennenberg, H., Mendel, R. R., Haensch, R. 2007. Sulphite oxidase as key enzyme for protecting plants against sulphur dioxide. Plant Cell Environ. 30 (4):447-455.

Li, W. X., Wang, Z. Y., Mi, G. H., Han, X. R., Zhang, F. S. 2001. Molybdenum deficiency in winter wheat seedlings as enhanced by freezing temperature. J. Plant Nutr. 24 (8):1195-1203.

Llamas, A., Otte, T., Multhaup, G., Mendel, R. R., Schwarz, G. 2006. The mechanism of nucleotide-assisted molybdenum insertion into molybdopterin. J. Biol. Chem. 281:18343-18350.
Márquez-Quiroz, C., López-Espinosa, S. T., Sánchez-Chávez, E., García-Bañuelos, M. L., De la Cruz-Lázaro, E., Reyes-Carrillo, J. L. 2014. Effect of vermicompost tea on yield and nitrate reductase enzyme activity in saladette tomato. J. Soil Sci.Plant Nutr. 14 (1):223-231.

Mendel, R. R., Leimkühler, S. 2015. The biosynthesis of the molybdenum cofactors. J. Biol. Inorg. Chem. 20 (2):337-347.

Miller, A. J., Cramer, M. D. 2005. Root nitrogen acquisition and assimilation. In Root Physiology: from Gene to Function, 1-36: Springer.

Pfaffl, M. W. 2001. A new mathematical model for relative quantification in real-time RT-PCR. Nucleic Acids Res. 29 (9):e45-e45.

Quackenbush, J., Cho, J., Lee, D., Liang, F., Holt, I., Karamycheva, S., Parvizi, B., Pertea, G., Sultana, R., White, J. 2001. The TIGR Gene Indices: analysis of gene transcript sequences in highly sampled eukaryotic species. Nucleic Acids Res. 29 (1):159-164.

Sun, X. C., Hu, C. X., Tan, Q. L., Liu, J. S., Liu, H. E. 2009. Effects of molybdenum on expression of cold-responsive genes in abscisic acid (ABA)-dependent and ABA-independent pathways in winter wheat under low-temperature stress. Ann. Bot. 104 (2):345-356.

Teschner, J., Lachmann, N., Schulze, J., Geisler, M., Selbach, K., Santamaria-Araujo, J., Balk, J., Mendel, R. R., Bittner, F. 2010. A novel role for Arabidopsis mitochondrial ABC transporter ATM3 in molybdenum cofactor biosynthesis. Plant Cell Online. 22, 468-480.

Tiedge, M., Lortz, S., Drinkgern, J., Lenzen, S. 1997. Relation between antioxidant enzyme gene expression and antioxidative defense status of insulin-producing cells. Diabetes 46 (11):1733-1742. 
Van Riet, L., Nagaraj, V., Van den Ende, W., Clerens, S., Wiemken, A., Van Laere, A. 2006. Purification, cloning and functional characterization of a fructan 6-exohydrolase from wheat (Triticum aestivum L.). J. Exp. Bot. 57 (1):213223.

Wan, Y. X., Liu, X. D., Li, Z. Y. 1988. Determination of soil available molybdenum and plant molybdenum by polarographic catalytic wave analysis. Soil Sci. Rep. China 1:43-46. (in Chinese with English abstract).
Yesbergenova, Z., Yang, G., Oron, E., Soffer, D., Fluhr, R., Sagi, M. 2005. The plant Mo - hydroxylases aldehyde oxidase and xanthine dehydrogenase have distinct reactive oxygen species signatures and are induced by drought and abscisic acid. Plant J. 42 (6):862-876.

Zaman, M., Zaman, S., Quin, B. F., Kurepin, L. V., Shaheen, S., Nawaz, S., Dawar, K. M. 2014. Improving pasture growth and urea efficiency using $\mathrm{N}$ inhibitor, molybdenum and elemental sulphur. J. Soil Sci. Plant Nutr. 14 (1):245-257.

Zimmer, W., Mendel, R. R. 1999. Molybdenum metabolism in plants. Plant Biol. 1 (2):160-168. 